\title{
REVIEW
}

Open Access

\section{Role of $\omega 3$ polyunsaturated fatty acids in diabetic retinopathy: a morphological and metabolically cross talk among blood retina barriers damage, autoimmunity and chronic inflammation}

\author{
Aldo R. Eynard* and Gaston Repossi*
}

\begin{abstract}
Vision disorders are one of the most serious complications of diabetes mellitus (DM) affecting the quality of life of patients and eventually cause blindness. The ocular lesions in diabetes mellitus are located mainly in the blood vessels and retina layers. Different retina lesions could be grouped under the umbrella term of diabetic retinopathies (DMRP).

We propose that one of the main causes in the etiopathogenesis of the DMRP consists of a progressive loss of the selective permeability of blood retinal barriers (BRB). The loss of selective permeability of blood retinal barriers will cause a progressive autoimmune process. Prolonged autoimmune injures in the retinal territory will triggers and maintains a low-grade chronic inflammation process, microvascular alterations, glial proliferation and subsequent fibrosis and worse, progressive apoptosis of the photoreceptor neurons.

Patients with long-standing DM disturbances in retinal BRBs suffer of alterations in the enzymatic pathways of polyunsaturated fatty acids (PUFAs), increase release of free radicals and pro-inflammatory molecules and subsequently incremented levels of vascular endothelial growth factor. These facts can produce retinal edema and photoreceptor apoptosis.

Experimental, clinical and epidemiological evidences showing that adequate metabolic and alimentary controls and constant practices of healthy life may avoid, retard or make less severe the appearance of DMRP. Considering the high demand for PUFAs $\omega 3$ by photoreceptor complexes of the retina, it seems advisable to take fish oil supplements ( $2 \mathrm{~g}$ per day). The cellular, subcellular and molecular basis of the propositions exposed above is developed in this article.

Synthesizer drawings the most relevant findings of the ultrastructural pathology, as well as the main metabolic pathways of the PUFAs involved in balance and disbalanced conditions are provided.
\end{abstract}

Keywords: Diabetic retinopathy, Inflammation, Autoimmunity, Rod and cones, Polyunsaturated fatty acids, Elderly

\footnotetext{
*Correspondence: aeynard@gmail.com; grepossi@fcm.unc.edu.ar

Instituto de Biología Celular, Histología y Embriología, Facultad de Ciencias

Médicas, INICSA (CONICET-Universidad Nacional de Córdoba), Córdoba,

Argentina
}

(c) The Author(s). 2019 Open Access This article is distributed under the terms of the Creative Commons Attribution 4.0 International License (http://creativecommons.org/licenses/by/4.0/), which permits unrestricted use, distribution, and 


\section{Introduction}

Diabetes Mellitus (DM) involving progressive alterations in metabolic and inflammatory indices comprising perturbations of the metabolism of glucose, lipids and proteins. Increases in the oxidative stress and alterations in glucose metabolism result in elevation of some inflammatory markers as leukotrienes (LTB4), interleukins-2 and 6 (IL-2 and IL-6), activation of toll-like receptor 4 and $C$ reactive protein [1-3].

The global increasing incidence of DM not only impacts the health of the affected individual but also enhances the cost of health care thus having implications for political, economic and social concerns for the society mainly in long standing aged diabetic patients $[4,5]$. DM is estimated to affect about 422 million people in the world actually and 1.6 million deaths worldwide were directly caused by diabetes in 2016 [6].

DM seems to be closely linked to scarce physical activity and inappropriate food intake resulting in obesity, insulin resistance, and eventually in metabolic syndrome [7]. One of the latest severe complication of DM in long standing patients is partial or total blindness preceded by others visual perturbations englobed in this article under the term DM-linked retinopathy (DMRP) $[8,9]$.

Increasing number of reports coincidently point out that a disbalance in the metabolism of $\omega 3, \omega 6$ and $\omega 9$ polyunsaturated fatty acids (PUFAs) occurs in obesity, insulin resistance, metabolic syndrome and DM $[1,10,11]$. In this regards it is comparatively less known the role played by disturbed PUFA metabolism in the DMRP-affected eye [8, 12]. The role of disbalanced metabolism of $\omega 3$ and $\omega 6$ PUFAs and their metabolites as lipoxins, resolvins, protectins and maresins in the development of a low grade chronic inflammation (LGCI) and its impact on the pathophysiology of DMRP have comprehensively been revised [13-15].

Plasma membranes (PM) of highly differentiated sacs and vesicles of retinal cones and rods of outer segment (OS) are unusually rich in long chain highly unsaturated-PUFAs (LCHU-PUFA) mainly $\omega 3$-docohexaenoic (DHA) and $\omega 3$-eicosapentaenoic (EPA) and $\omega 6$-arachidonic (AA) [16, 17]. Phospholipids (PL) containing these LCHU-PUFAs are heavily concentrated in PMs of OS which are in risk of becoming abnormal because relative deficiency of $\omega 3$ LCHU-PUFAs [18, 19].

Human retina is a privileged and "sequestrated" highly differentiated neural cell populations without further contacts with the own immunological system (IS) of each individual [20, 21] precluding a significative role for autoimmune responses in the pathophysiology of DMRP. This possibility have been earlier proposed by Rahi and Addison in 1983 [22] and others whom critically discussed cardinal findings in DMRP [21]. Frequent abnormalities in retinal tissues of DM subjects comprise higher levels of anti-pericyte and anti-endothelial cell autoantibodies, increased levels of tumor necrosis factor-alpha (TNF- $\alpha$ ), several pro-inflammatory interleukins and lymphokines in the serum and vitreous, increased deposits of immunoglobulins in pre-retinal membranes and activation of complement system [23]. DM subjects showed higher values of several leukocyte antigens and their receptors on retinal blood vessels and pigmented epithelial cells (PEC). Described elevated levels of autoantigens against retinal epitopes and increased expression of their receptors observed on DMRP are similar to those registered in many other nonlymphoid cells populations in several autoimmune diseases [24], including type 1 DM [25]. Hence this abnormal expression of neo-antigens in retinal neuron cells seems to be part of a progressive autoimmune response [26].

The role played by abnormal metabolism of PUFAs $\omega 3$ and $\omega 6$ and their metabolites and their impact on development of LGCI on DMRP have been discussed [8, 27, 28]. In this review the aim is highlight the morphological-linked perturbations in retina as a whole, and particularly those changes observed in the inner and outer blood retina barrier $(\mathrm{BRB})$ and photoreceptors, in the framework of a functional/ metabolically deficiency of $\omega 3$ LCHU-PUFAs, topics scarcely integrated in these issues.

\section{Human retina \\ Histogenesis and neural cell populations in human retina}

The histogenesis of the human neural retina involves complex genetic and epigenetic sequential processes controlled by on/off switching of genes groups modulating waves of neuroblasts proliferation, differentiation, migration, selective apoptosis and angiogenesis being some of these stages bizarrely reactivated in DMRP $[29,30]$.

Genetic planification and expression of human retina development involve several progenitor genes (such as LIN28B, FGF19, PRTG, and SFRP2) [31]. Interestingly, SFRP2 overexpression has been linked to obesity, insulin resistance and increased vascular endothelial growth factor (VEGF) [32]. Since human retina is a prolongation of the central nervous system (CNS) its highly differentiated neural cell populations and their bulk of expressed new molecules (potential epitopes) will remain sequestrated within their own compartments and without further contacts with the still maturating IS of each individual [20, 21, 33]. Eventual leakage of these molecules in after born life (by trauma, diseases, infections, inflammation, etc.), some of them having antigenic capability against the IS, may start a slow and subtle autoimmune-like response [21, 22] thus becoming one of the events contributing to the LGCI which strongly lies in the pathophysiology of DMPR $[14,15]$.

\section{Morphological bases of the major components of the inner and outer blood retina barrier (iBRB and $O B R B$ )}

Human retina is isolated from the rest of eye cell populations by an elaborated continuous blood retina barriers 
which may be divided into inner, or vitreal side (iBRB) composed by Müller cell layer and the inner limiting membrane and the choroidal side or outer (oBRB), built by PEC, Bruch membrane and basal membranes and endothelia of choriocapillaris. The boundaries are sealed by the ora serrata in the periphery as described below.

Ultrastructure of Müller cells and its BM, the major components of the inner limiting membrane: Among the somae and their intricated prolongations of different neuronal populations, there are intermixed the glial projections of Müller cells, whose dendriform projections play a very important role isolating neurons somae and their prolongations thus establishing the precise neuronal distribution in the different layers of the neural retina. Projections of Müller cells sealed by tight junctions (zonulae occludens, $\mathrm{ZO})$ zonulae adherens (ZA) and gap junctions plus its own BM (inner limiting membrane) conform the morphological base of iBRB, sequestering retina cell populations from the vitreal environment (Fig. 1) [34-37].

Ultrastructure of pigment epithelium cells (PEC) and choriocapillaries, main components of the outer limiting membrane: A single layer of PEC lies on Bruch membrane being this its own basal membrane (BM). BM of PEC is in close contact with small blood vessels and capillaries running throughout the choroid choriocapillaris network whose endothelial cells are fully sealed by continuous $\mathrm{ZO}$ and $\mathrm{ZA}$ turning not permeable this boundary as also happens with those capillaries forming the basis of the whole hemato-CNS barrier [38, 39] (Fig. 2). It is worth to mentioning that, in contrast, there is not $\mathrm{BM}$ between PEC projections and photoreceptors (PRs) outer segments of rod and cones [40]. PEC are tall and very thin with numerous prolongations having a supranuclear Golgi. Both PEC and Bruch's membrane are as slender as $15-20 \mu \mathrm{m}$ thick. PEC is a very particular population since has highly specific appetite to continuously phagocyte aged, worn out or damaged membranous disc tips of the OS of PRs [41]. Prolongations of PEC build up a dense net of interdigitations among the OS of cone and rods. Cytoplasm of projections are filled with mitochondria indicating a high demand of energy for active molecules traffic. Contiguous surfaces of PEC digitations are continuously sealed by arrays of junctional complexes (ZO, ZA and gap junctions) $[34,35,42]$. These ultrastructural differentiations are strongly reminiscent to the assemble of junctional complexes observed in Sertoli cells surrounding maturing spermatogonia progenies, where reside the morphological bases of the hematotesticular barrier [43]. The apex of PECs prolongations totally stuff the interstitium among the slender OS of rods and cones building capsule-like cylindrical processes and intricated delicate prolongations. These PEC processes contain abundant melanin bodies and variable amounts of myelin-like (lamellar) bodies which are debris of phagocytosed aged OS rests of rod and cones in variables processes of digestion, having phospholipases activities [44-46] releasing LCHU-PUFAs to be reutilized in plasma membrane synthesis as well as pro-oxidant moieties [47]. PEC prolongations show a rich network of cisternae of agranular ER. Hence, the BM of PEC plus the complex array of ZO, ZA and tight junctions which seal the intercellular spaces conform one the major barrier of the retina on the choroidal side. In addition, choriocapillaris possesses continuous endothelial cells and $\mathrm{BM}$, without fenestrations being per se highly impermeable. Prolongations of PEC and BM of choriocapillaris are in closed and uninterrupted contact thus fully sealing retina with respect the choroidal side (Fig. 3) [34, 35, 42, 48, 49]. So, leakage in and out from choroid blood vessels and retina is normally avoided. This is important since many retinal antigenic determinants expressed in later prenatal period and many others molecules to be eventually expressed along the life span of the subject [22, 33, 41, 50] will remain sequestrated within retina environment without further contact with the IS of the individual in normal conditions.

\section{Disruption of BRBs in DMRP}

Several research shows that PEC becomes altered in DM allowing increased leakage from choroid blood vessels together with delayed reabsorption of extracellular fluids being this one of the causes of retinal edema [51]. It is generally assumed that the disruption of the $\mathrm{BBRB}$ is a major cause of DMRP $[36,52]$ but there is also evidences that the disruption of the external limiting membrane and PEC causing oBRB damage also contributes to the pathogenesis of DMRP as observed in diabetic models [53-55]. In an experimental model of type 2 $\mathrm{DM}$, the GK rats, oBRB damage is linked to the formation of clefts through the PEC prolongations which enables diapedesis of inflammatory cell between the retina boundary and choroid [50]. In addition Müller glial cells show increased ballooning [56] due to ER and mitochondrial swelling which are constant ultrastructural findings in DM [57] and also when $\omega 3$ and $\omega 6$ PUFA deficiency (w3/w6D) occurs [58]. Actually, slow dissolution of inter-vascular junctions, which result in vascular leakage and retinal edema favors LGCI [59].

w3/w6D induces disruption of several cellular barriers increasing the leakage of macromolecules from blood vessels into extravascular environment: Consistent research in animals and humans suffering of variables degrees of nutritional or metabolically w3/w6D result in a wide cellular and molecular abnormalities of key molecules involved in several cell-cell, cell-BM adhesion and consequently breakdown of several limiting 


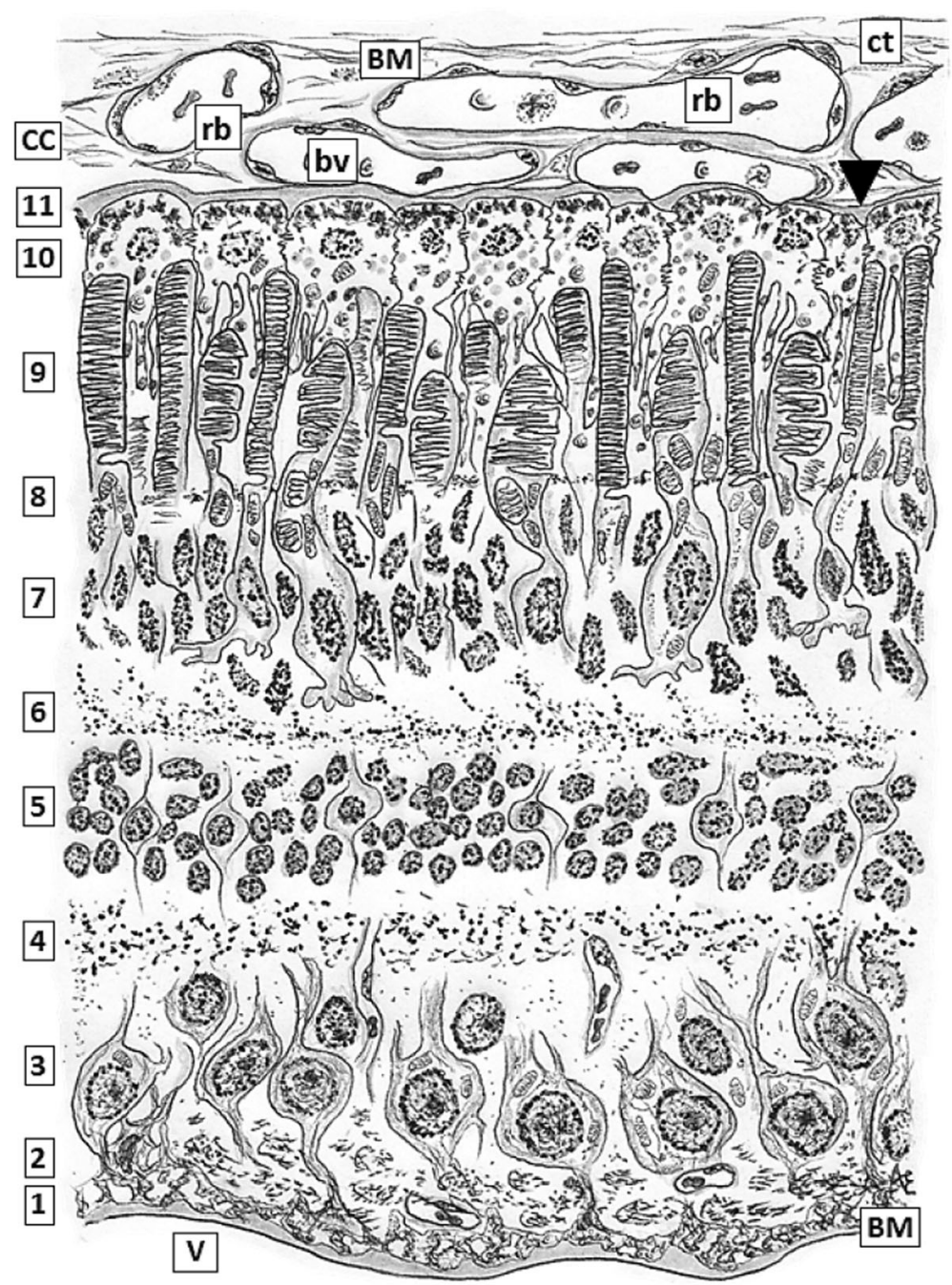

Fig. 1 Layers of the normal retina. Low magnification: 1, inner limiting membrane bordering the vitreal body (V) constituted by a thin basal lamina, Bruch Membrane (BM). The opposite face of this BM shows delicate projections of Müller glial cells sealed each other by scattered tight junctions just above the BM; 2, layer mainly constituted by axons of ganglion neurons which form the optic nerve at the papilla;3, ganglion multipolar neurons layer; 4, inner plexiform layer; 5, inner nuclear layer; 6,outer plexiform layer; 7, outer nuclear layer; 8, outer limiting layer where abundant Zonulae adhaerentes (ZA), belt- shaped, are located between the photoreceptor neurons and the tinny terminals of Müller's glial cells; 9, inner and outer segments of rods and cones layer; 10, pigment epithelial cells with varieties of junctional complexes between them . Richness in tight junctions plus normal integrity of Bruch membrane constitute the major morphological bases for the blood-retinal barrier; 11, Bruch membrane, a thin basal membrane (indicated with a black triangle, $\boldsymbol{\nabla}$ ) that adjoins to the extracellular spaces of chorio-capillaris (CC) or Choroidea, the medium layer of the eyeball showing abundant small blood vessels (bv) mainly fenestrated capillaries with a thin continuous BMs and venules containing scarce red blood cells (rb) distributed within scarce loose connective tissue (ct)

barriers also linked to the appearance of abnormal fatty acids (FA) as previously reported [58, 60-63].

Once metabolically, or nutritional, w3/w6D is established, a progressive breakdown and leakage appears in many epithelial/stromata barriers, which in turn become propitious scenarios to the slow developing of LGCI [64]. Two examples will be briefly described since some morpho-functional similarities exist regarding BRB among retina tissues and several epidermoid and urothelial epithelia interphases. In rodents increased loss of water through skin, with increased hyperplasia, hyper- and para-keratosis and scaliness is observed in epidermis and other Malpighian epithelia as esophagus and forestomach, indicating damage to the water barrier function [65]. Reduction of the number of desmosomes has also been reported in the small bowel intestinal epithelia, forestomach and esophagus $[46,65,66]$ resulting in abnormal gastrointestinal absorption in w3/w6D [67]. Blood vessels in dermis and in other organs of w3/w6D animals showed vasodilatation with notorious extravasation of lymphocytes, monocytes and polymorpho nuclear leukocytes (PMN) [58, 60, 68, 69]. In these barriers paracellular permeability is mainly 


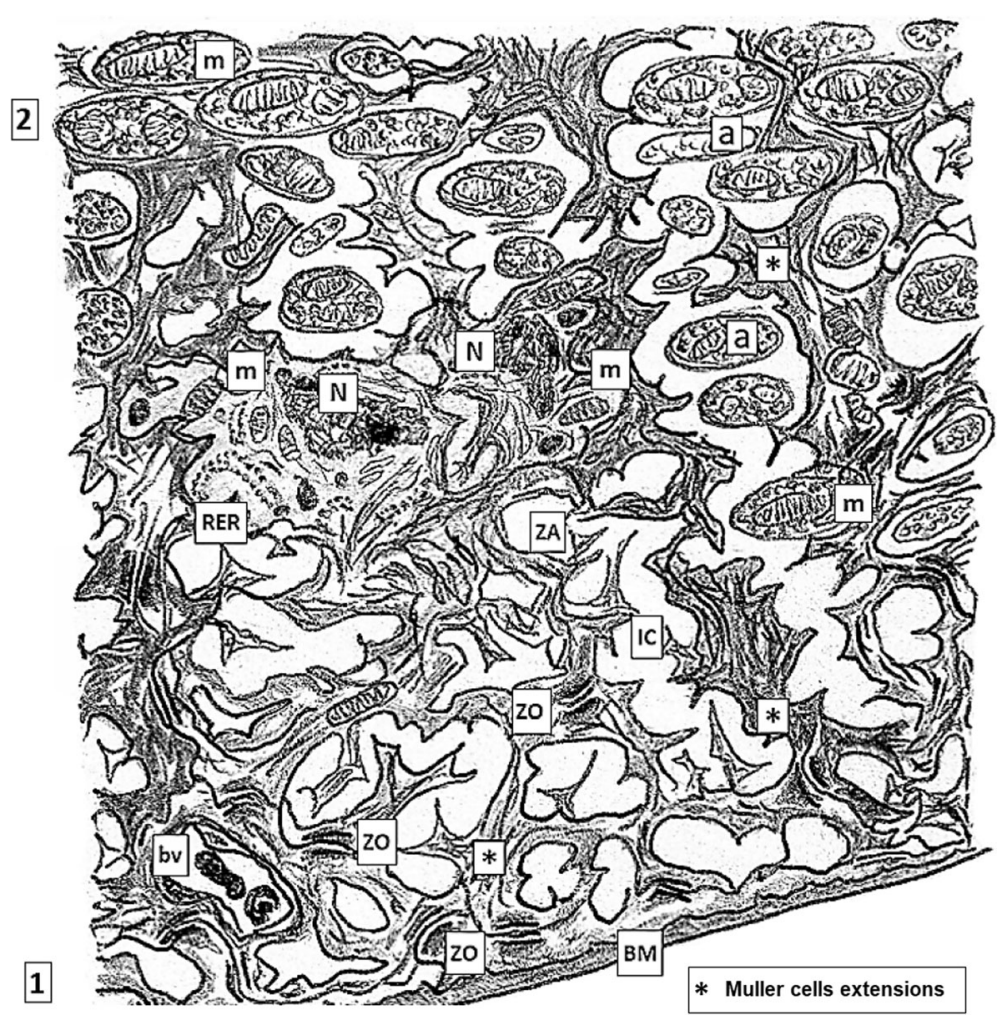

Fig. 2 Higher magnification of the layers 1 and 2 of normal retina as depicted in Fig. 1. It is mainly constituted by axons obliquely sectioned (a) of ganglion neurons and inner limiting layer with nuclei $(\mathrm{N})$ of two Müller cells and their delicate extensions $\left({ }^{*}\right)$ containing some organelles (mitochondria -m-, RER) and neurofibrils, leaning on the inner Bruch membrane (BM). Some few small blood vessel (bv) are identified. Developed tight junctions complexes (zonulae occludens and adherens, ZO, ZA) plus normal morpho-functioning of Bruch membrane are the main morphological bases for the vitreal-retinal barrier. Dilated intercellular spaces (IC), although drawed here as usual artifacts induced by processing, may become susceptible areas for the onset of microedema and then progression to cystoid degeneration (compare with Fig. 4)

regulated by the structure and functions of occludins tight junctions and $\mathrm{ZO}$ and $\mathrm{ZA}$. Occludins interacts each other in contiguous cells building the major barrier in several endothelia being a main key array for the blood-brain barrier and for BRB in the eye, too. Desmosomes represent one of the key cell-cell adhesion mechanisms in epithelia, endothelia, cardiomyocytes, and particularly in Malpighian epithelia (as skin, esophagus, corneal and ora serrata in the eye) among others [70]. Desmosomes are composed of desmoglein 1, 2 and 3 together with desmocollins 1, 2 and 3 , collectively named as desmosomal cadherins [71]. When E-cadherin negative epithelial cells are cultured with $\omega 6-$ GLA, a LCHU-PUFA, tighter cell-cell association developed when compared with controls. Immunocytochemical and electron microscopic studies revealed that this adhesion was mediated by desmosomes showing heavy marking for desmoglein [72]. On the other hand, $\omega 3$ and $\omega 6$ PUFAs regulate cell-matrix adhesion, an important crossroads for morpho- and functional integrity of blood-tissues barriers as a whole $[62,73,74]$.

When inflammation process starts the first steps is vasodilatation with slowing down of the erythrocytes flux and adhesion to the surface of endothelium being now $\mathrm{ZO}$ and ZA among endothelial cells the major barriers in charge of control the input and output of several molecules (Figs. 4 and 5). Members of the $\omega 3$ PUFAs family are able to modify certain functions of the tight junction in vascular endothelial cells, as the trans-endothelial resistance and the paracellular permeability $[75,76]$.

The other example of barrier disruption and the role exerted by LCHU-PUFAs, is located in the luminal surface of mammals urinary tract built by urothelial umbrella cells which totally covers pelvises, ureters and bladder and are strongly modified by PUFAs composition [64]. Luminal urinary surface showed polygonal areas of big clustered glycoproteic particles, the uroplakins, which show a strong morphological resemblance to visual pigments, heavily packed in PM of retinal rod and cones. Along with $\mathrm{ZO}, \mathrm{ZA}$ and other cell-cell union complexes, the PM built the main morphological component of the "permeability barrier" of urothelium [77, 78]. So, leakage of putative antigens, mutagens, and other toxic molecules from urine into the chorionic blood vessels is halted. However, umbrella cells require 


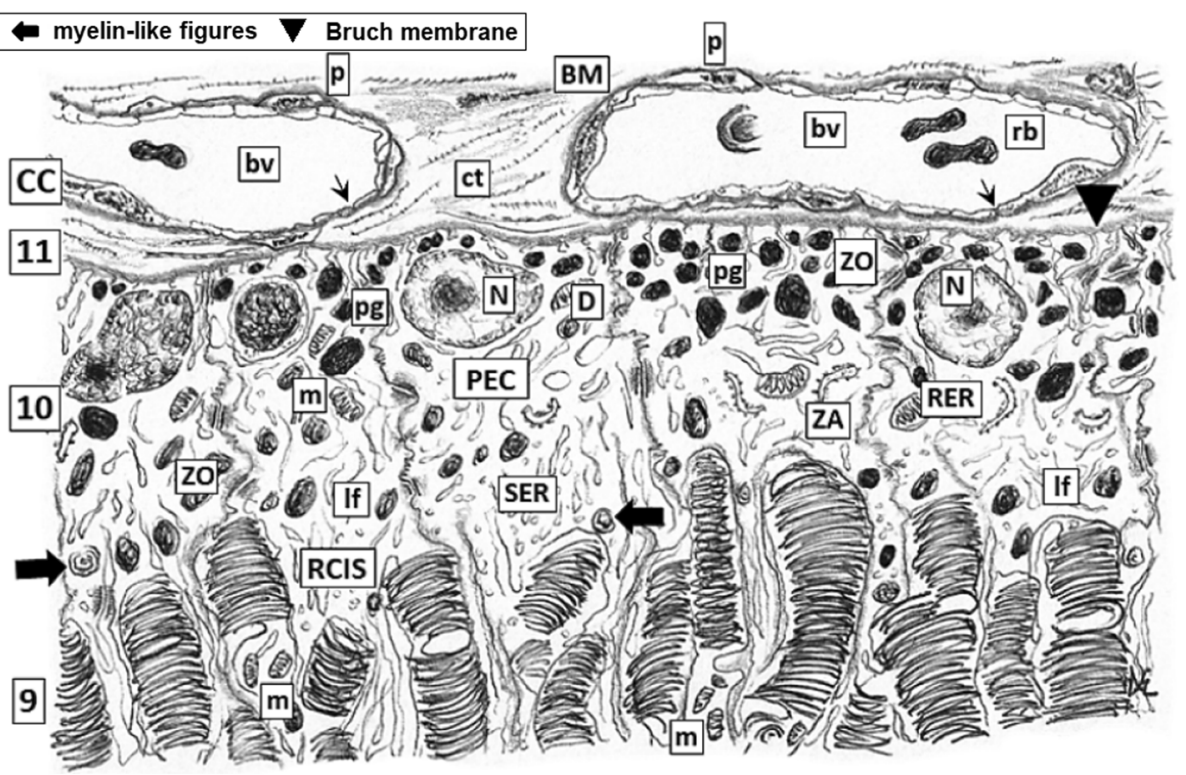

Fig. 3 Higher magnification of the layers 9 to 11 plus CC of normal retina as depicted in Fig. 1. Fenestrated endothelia (arrows) with thinny BM and some pericytes ( $p$ ) of bv within loose ct of CC layer which locate closer to Bruch membrane (indicated with a black triangle, $\mathbf{\nabla}$ ):; rods and cones inner segments (RCIS) are deeply allocated within entangled thin processes of PEC. The basal plasmalemma of PEC, underlying the BM, have complicated recesses sealed by ZO, ZA and desmosomes (D). Within these processes abundant pigment granules (pg) and lysofagosomes (If) are visualized intermixed within a vast and intricated network of cisterns and vesicles of smooth endoplasmic reticulum (SER). Few aged sacs of rod and cones partially digested appears as myelin-like figures (filled black arrow)

of a fast turnover of PM, as also happens in retinal rod and cones, being these continuously synthesized with a constant high requirement of essential PUFAs. The $\omega 3$ and $\omega 6$ LCHU-PUFAs play a key role in the maintenance of the molecular structure and functions of urothelium barrier against putative pathogenic and injurious molecules carried by urine $[79,80]$.

Cited examples of intake/administration/metabolism disbalances of LC-PUFAs strongly evokes similarities with scenarios on eye BRBs, the turnover of the highly specialized plasma membrane of OS PLs of rod and cones and their high demand of $\omega 3$ and $\omega 6$ LCHU-PUFAs.

\section{Ultrastructure of rod and cones and roles of membrane PUFAs for photoreceptors}

Rods are tall, long and thin highly specialized neurons ordered in palisade array whose apical side are choroid-oriented to the apex face of PEC (Figs. 1 and 3). Rod axons establish synapses with other neurons in the innermost layers of the retina. Their apical segment, as happens in cones too, is highly differentiated in two segments: outer (OS) and inner joined by a thin portion of cytoplasm. The OS of rods contains the integral membrane glycoprotein (GP) rhodopsin. OS is heavily loaded with a large number of closed membranous sacs, which overlap as pancakes stacked in a perpendicular array respect to the major axis of the rod. Rhodopsin and others GPs visual pigments move along and within (flip-flop) the phospholipid bilayer thus being their functionality fully dependent of the viscosity/fluidity balance of the sacs membranes, fact which in turns is mainly determined for the relative ratio of $\omega 3 / \omega 6 / \omega 9$ PUFAs and cholesterol $[81,82]$. Rods are distributed by the retina together with the cones but are better adapted for vision with little light intensity or twilight vision (scotopic vision), which does not allow a proper the perception of colors. Interestingly, this kind of crepuscular vision remains better preserved in DMRP [83, 84].

Cones make up a population of about 120 million of thin, highly polarized neurons, about $100 \mu \mathrm{m}$ in length, with their major axis perpendicular to the surface of the retina and also encastrated within complex interdigitations of PEC. Cones gathers in the fovea centralis, an area without blood vessels where the remnant layers of the retina are very thin being towards this zone where our eyes clearly project the objects of the outside world (photopic vision). Worth to consider, incoming and outcoming bunch of eye blood vessels and nerves are morphologically isolated from retina cell population by elaborated complex union as previously described built by oligodendroglia, pericytes and impermeable blood vessels of the CNS. Proinflammatory bioactive lipids (BLs) derivative molecules, as eicosanoids, leukotrienes (LTs) and cytokines released from macrophages, endothelial cells and other cells, may migrate from small blood vessels and choriocapillaris crawling towards the 


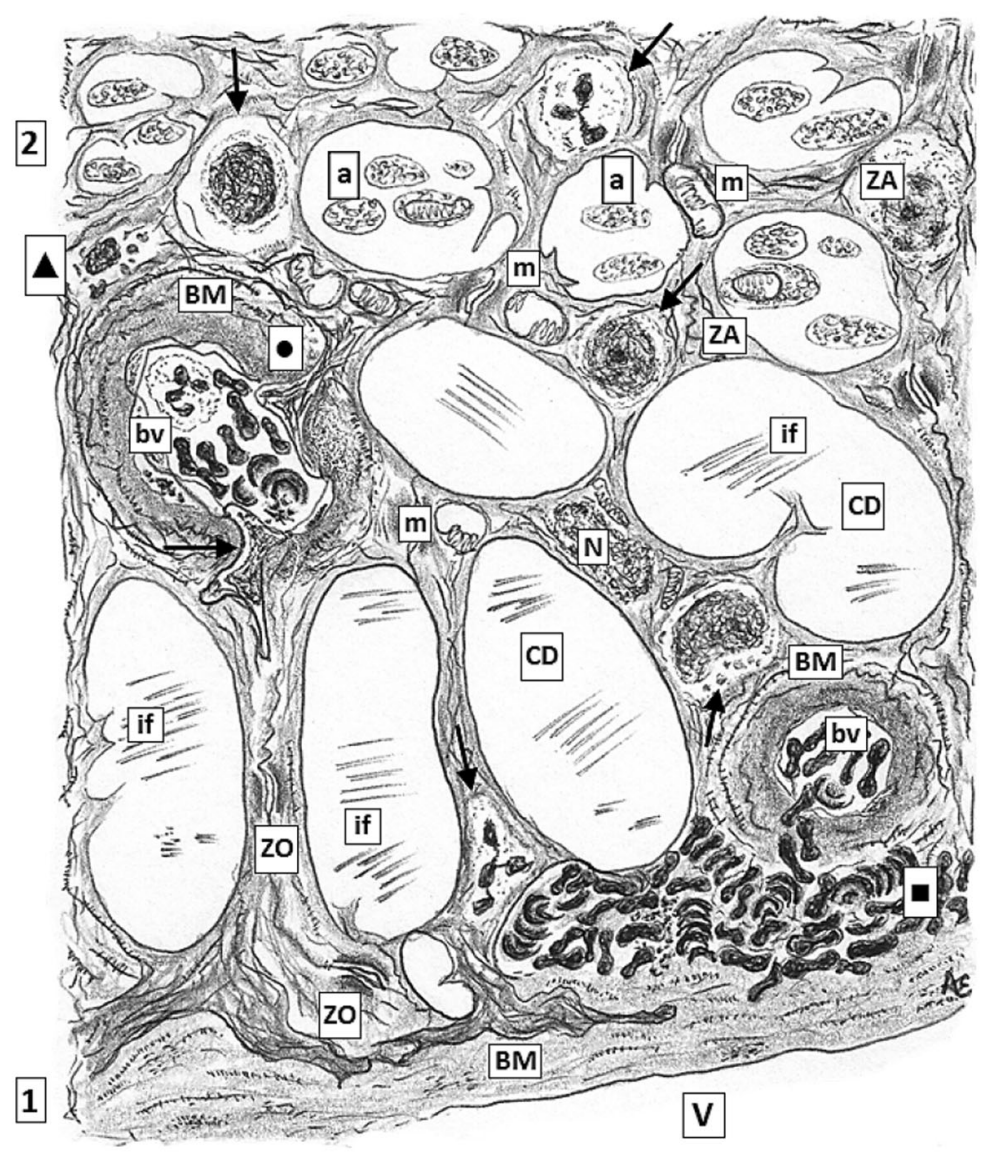

microhemorrhage $\bullet$ damaged basal membrane $\Delta$ apoptocic nucleus $\rightarrow$ plasmocytes

Fig. 4 Human retina of diabetic patient with advanced DMRP. This picture illustrating layers 1 and 2 as identified in Fig. 1. Also compare with Fig. 2. Microhemorrhage (indicated with a black square, $\mathbf{m}$ ) from heavily congested bv pouring out rb and inflammatory cells within augmented perivascular collageno-genesis in ct interstitium. Cystoid degeneration (CD) appears as enlarged and coalescent bubbles arising within IC containing coarse bundles of intermediate filaments (if). Thickened Bruch membrane bordering the vitreous body and BMs of bv are characteristic features of DMRP diapedesis of inflammatory cells (polynuclears, lymphocytes) and wandering plasmocytes are pointed (arrows). Swollen mitochondria are frequently seen in axolemma of the layer 2 of axons of ganglion neurons and cytoplasmic projections of Müller glial cells overloaded with coarse bundles o neurofilaments some of them invading the lumen of bv through damaged BMs (indicated with a black circle, $\bullet$ ) whereas others are deeply anchored within Bruch membrane. Incontinent or damaged ZO and ZA are shown. Apoptotic Müller cell nucleus (indicated with a black triangle, $\mathbf{\Delta}$ )

choroids and retina when the selective barriers described above became progressively damaged. These proinflammatory molecules have facilitated their access to the neighbors OS of cone and rods due to the lack of a distinctive basal membrane between retina and choroids.

\section{Metabolism of PUFAs and DMRP \\ PUFAs in health. PUFAs metabolism is altered in DM}

As depicted in Fig. 6 and briefly explained in the legend, PUFAs have at least two major functions: as a major component of cell membranes bilayers and as precursors of many BLs. Under normal physiological conditions most of BLs derived from $\omega 6$-AA, $\omega 3$-EPA and $\omega 3$-DHA as lipoxins, resolvins, and protectins tend to maintain normal homeostasis and avoid the initiation of LGCI in DM $[85,86]$.

Relative metabolically/functionally w3/w6D may occur more often than believed. This deficiency may occur if one or more of three circumstances appear: 1- lack of essentials $\omega 3 / \omega 6$ PUFAs intake in the diet, likely to be seen in less developed societies; 2- unhealthy intake of fats and lipids in the diet, such as excess consumption of saturated FA, hydrogenated vegetable oils and other non-Essential Fatty Acids (EFAs), mainly $\omega 9$ precursor (i.e. transgenic corn/ sunflower oils enriched in oleic acid,OA, 18:1 $\omega 9$ ) which $\mathrm{vol} / \mathrm{vol}$ compete with $\omega 3 / \omega 6$ PUFAs metabolism (see legend Fig. 6). 3- Abnormalities in the metabolism of FA, as certainly happens in DM, as will be described. Although 


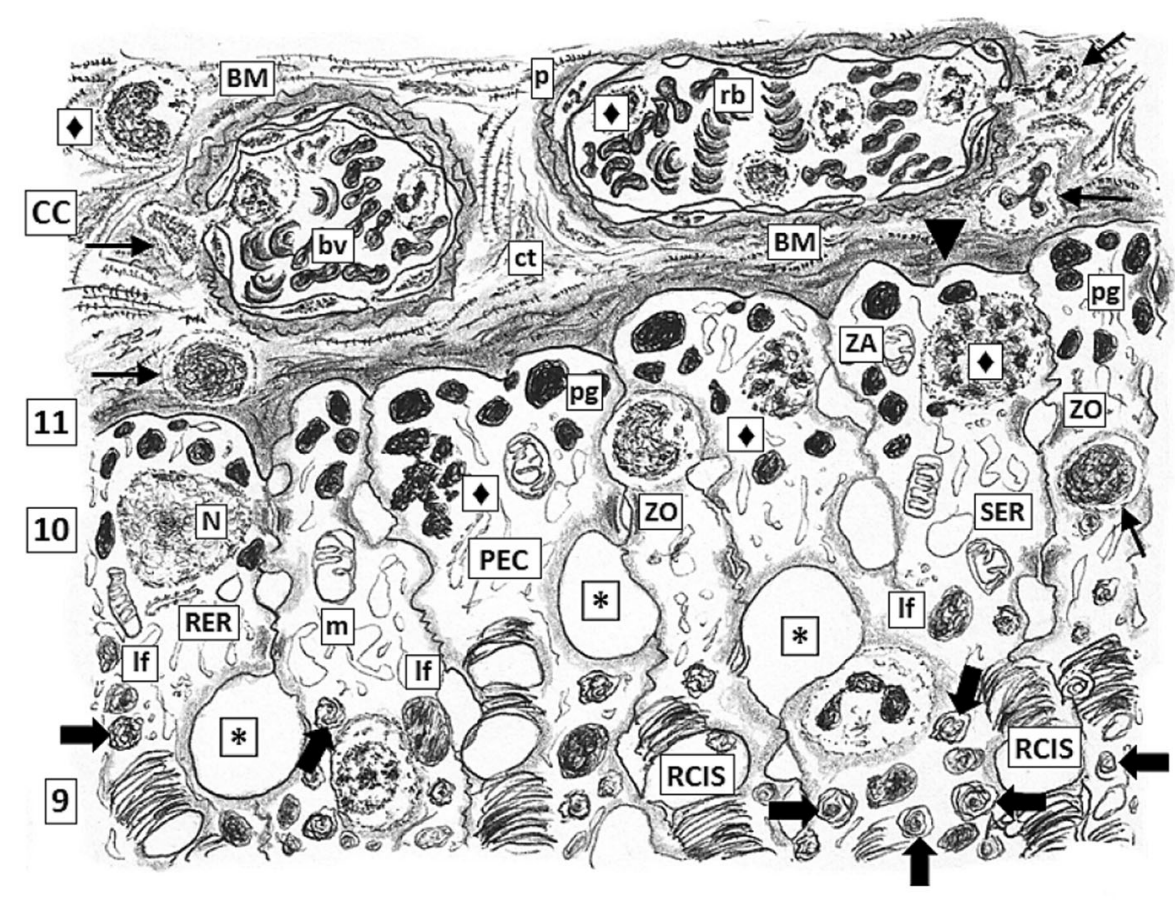

Bruch membrane $\rightarrow$ plasmocytes $\bullet$ apoptotic cell $*$ intercellular vacuoles $\leftrightarrow$ myelin-like figures

Fig. 5 Higher magnification of the layers 9 to 11 plus CC of human retina of diabetic patient with advanced DMRP; as identified in Fig. 1. Also compare with Fig. 3. Congested bv in CC layer showing increased perivascular collagen genesis in coarse ct interstitium. Thickening of Bruch basal membrane (indicated with a black triangle, $\mathbf{\nabla}$ ) bordering against CC layer and BMs of bv are characteristic features of DMRP at this stage. Diapedesis of inflammatory cells (polynuclears, lymphocytes) from bv and wandering plasmocytes are pointed (arrow). There are scarce pericytes some of them in apoptosis (apoptotic cells were indicated with a black diamond, $\bullet$ ). Swollen mitochondria and vesicles of SER are frequently seen in cytoplasm of PEC, whose nuclei are in diverse stages of apoptosis. Incontinent or damaged ZO, ZA are identified thus facilitating the development of large PEC intercellular vacuoles $\left(^{*}\right)$ which in turns collaborate in the worsening of retinal edema. Few rods and cones inner segments (RCIS) are visible, most of them degenerated and vacuolated. Closer PEC recesses are filled with increased number of lyso-phagosomes (If) and myelin like figures (indicated with a filled black arrow) containing aged sacs membranes in diverse stages of digestion

industrial societies have almost eradicated the w3/w6D from insufficient intake of EFAs, items 2 and 3 become risky situations for both rich and poor countries, with the aftermaths of metabolic syndrome, obesity, dyslipidemias, DM and their late complications as DMRP $[1,2,4,87]$.

We showed that abnormal LCHU-PUFA, like eicosatrienoic acid $(20: 3 \omega 9)$ produced by an imbalance in metabolism of different series of FA, a marker of w3/w6D, was able to down-regulate the expression of both E-cadherin and desmoglein in squamous skin cells, key molecules for the adequate sealing of epithelial-conjunctive barriers [61, 88]. As discussed, when a metabolically w3/w6D occurs there is weakened expression of cell adhesion molecules and cellcell adhesiveness, which appears to be involved in certain pathological features as losses of functions of several barriers involving endothelia, cell- cell and cell-matrix interactions as described above (summary in Fig. 7).

LCHU-PUFAs together with cholesterol can regulate membranes particular properties as fluidity/viscosity and in turns they modulate their dynamics and biophysical properties [89] and lateral segregation of membrane glycoprotein as happen with visual pigment of rods and cones. The visual macromolecules of the pigment must be densely packed, ensuring an optimal exposure to the photons, for their correct functioning so changes in the membranes can affect this arrangement [90-92].

In DM the metabolism of PUFAs is clearly abnormal, insofar as there is a partial loss of the enzyme delta-6-desaturase activity, which catalyzes the initial desaturation step in the pathways involved in the synthesis of longer chain PUFAs, whose disponibility becomes progressively diminished [15, 28, 93, 94]. Gong et al. (2017) reviewed these issues concluding that dietary $\omega 3$-LCHU-PUFAs reduce retinal and choroidal neo-angiogenesis. $\omega 3$-LCHU-PUFAs BLs metabolites from COX2 and LOX are generally inhibitors whereas $\omega 6$-LCHU-PUFAs metabolites promote inflammation and angiogenesis. However, the $\omega 3$ and the $\omega 6$ lipid products of cytochrome $\mathrm{P} 450$ oxidase $2 \mathrm{C}$ promote neovascularization in retina and choroid, suggesting that inhibition of this pathway might be beneficial in prevention and treatment of DMRP [8]. 


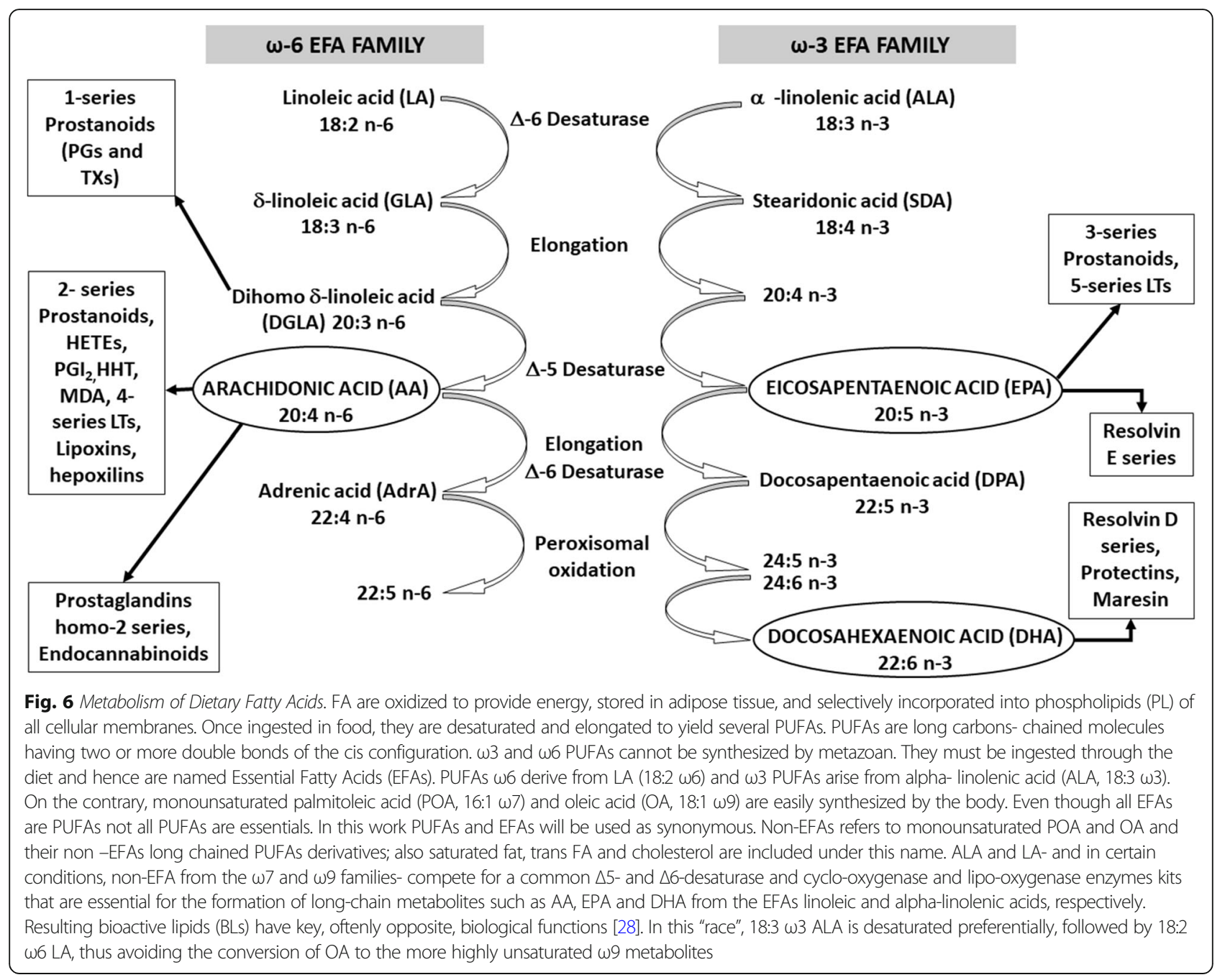

\section{PUFAs alteration in DM resembles w3/w6D}

As quoted above, a relative deficiency of $\omega 3$ EPA and DHA and $\omega 6 \mathrm{AA}$, or excesses of $\omega 9$ food intake, may predispose to the development of DM. Patients with types DM1 and DM2 have decreased plasma and tissues concentrations of AA, EPA and DHA whereas $\omega 9$ FA derivatives are increased in their plasma phospholipid fraction [1, 4, 95]. These findings give further support to the concept that disbalanced metabolism of PUFAs may have a significant role in the pathobiology of DM and their complications in membranes phospholipids heavily dependent of $\omega 3$ and $\omega 6$ LCHU-PUFAs supply, as is mammal retina [14, 18, 96].

\section{PUFAs changes in PR membranes in DM and $\omega 3$ and $\omega 6$ deficiency (w3/w6D)}

A strong association between dyslipidemia and the development of diabetic retinopathy was revealed by results of the Diabetes Control and Complications Trial/ Epidemiology of Diabetes Interventions and Complications cohort study [97].
In vivo experiments in Rhesus monkeys shows that a diet low in $\omega 3$ PUFA (ALA or DHA) was associated with specific perturbations in retinal function, including increased implicit times and a substantial delay in the recovery of the rod-isolated photoresponse. Rod sensitivity was reduced by $40 \%$ in the long standing dietary $\omega 3$-deficient monkeys and the onset of the rising phase of the photoresponse and rod recovery were also significantly delayed [98]. These alterations appear to be linked to dimminution in retinal DHA levels that may alter biophysical properties and lipid-protein interactions in retinal membranes where visual pigments are inserted.

Early-stage diabetes induced a marked decrease in elongases expression. These fact produce a significant reduction in total retinal DHA and diminished incorporation of LCHU-PUFAs into retinal phosphatidylcholine. The decrease in $\omega 3 / \omega 6$ PUFAs ratio in retina is associated with an increase in gene expression of proinflammatory markers IL6, VEGF, and intercellular adhesion 


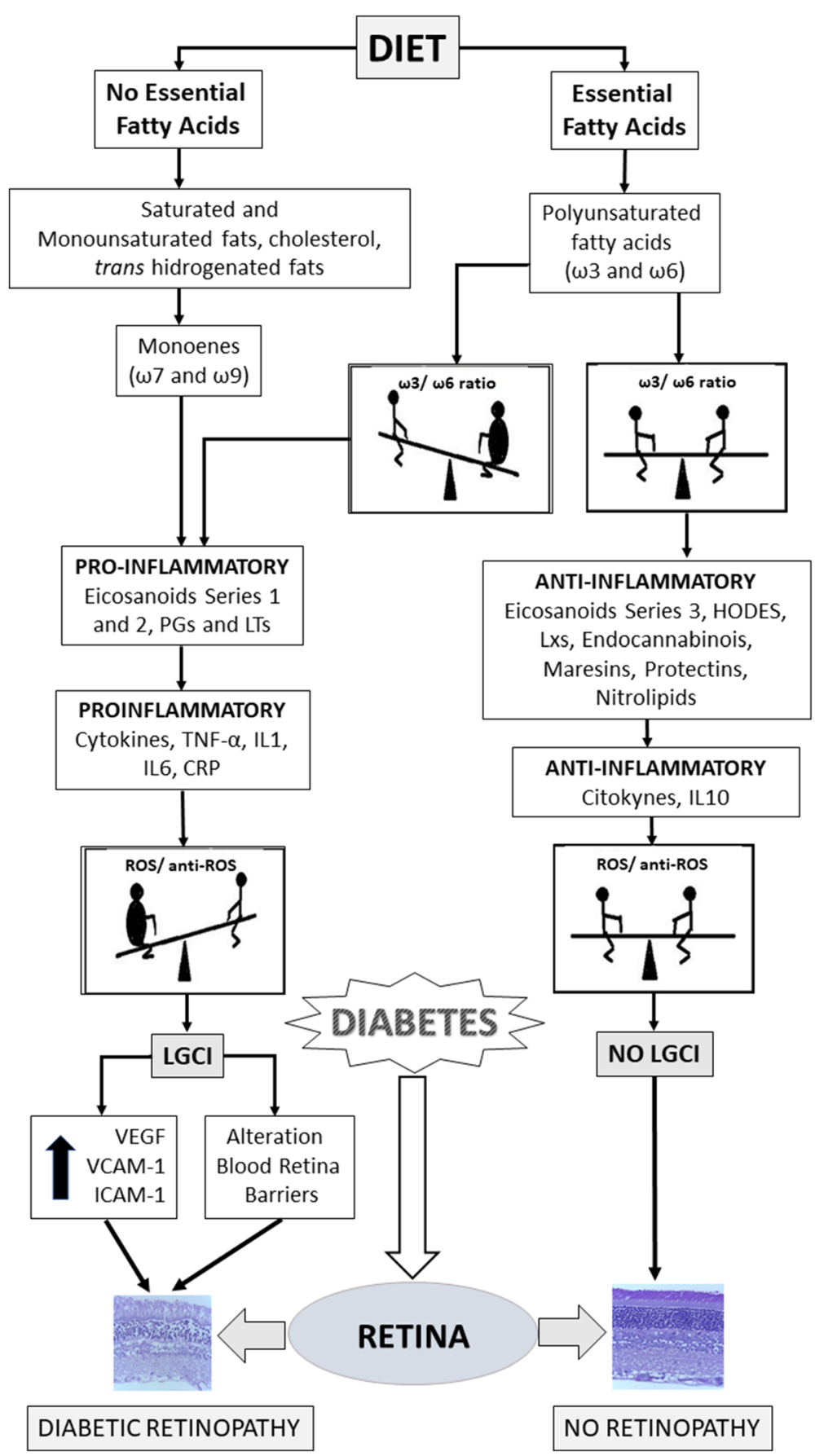

Fig. 7 Fatty acids, inflammation and diabetic retinopathy. Role of dietary fatty acids, bioactive lipidic metabolites and LGCl and to risk for diabetic retinopathy

molecule-1 (ICAM-1) thus creating an LGCI environment that contributes and maintains the development of DMRP $[14,18]$.

In addition, deficiency of LCHU-PUFAs, and low $\omega 3 / \omega 6$ PUFA ratios occur in human retinas with macular degenerations. Quality of lipids foods certainly influence human retinal $\omega 3 / \omega 6$ ratios, which may explain why a diet high in $\omega 3$ rich fish oil (DHA and EPA) is beneficial against macular degeneration as pointed out in some epidemiologic studies [81, 99].

Streptozotocin-diabetic rats showed decreased desaturase and elongase activities and alterations in rod function exacerbated by low intake of dietary $\omega 3$ PUFAs. A decrease in retinal DHA was found $(171 \%)$ in diabetics animals fed deficient $\omega 3$ diet $[8,96]$. 
In summary, some epidemiology, clinical and experimental research coincidently show that a decrease of retinal $\omega 3$ levels, increase of oxidative stress and proinflammatory metabolites are common factors that are involved in the pathophysiology of photoreceptor death in several degenerative diseases of the retina including DMRP. On the contrary high levels of DHA synthetized by retinal metabolism protects retina PRs from apoptosis induced by oxidative stress and promotes their differentiation $[8,17]$.

PUFAs in rod and cones outer segments. Perturbations in DM In normal conditions, LCHU-PUFAs are particularly enriched in vascular retina, being the bulk of DHA and AA around $10 \%$ of isolated membranes of retinal capillaries and surrounding pericytes [100]. Radiolabeled $\omega 3$ LCHU-PUFA precursor given intraperitoneally or orally to healthy rats is first localized in the liver and one hour later labeled DHA was detected in rods. DHA and docosapentaenoic acid (DPA, 22:5 $\omega 6$ ) are avidly incorporated in PRs membranes of rods and cones reaching a peak at $24 \mathrm{~h}$ after infusion. PRs incorporate $\omega 3$ and also $\omega 6$ LCHU-PUFAs 3-5 times more efficiently that PEC does $[101,102]$. LCHU-PUFAs are then convoyed to the smooth endoplasmic reticulum (ER) located in the myoid (the basal area of the OS) of PRs and then into a variety of membranes PLs and triglycerides. LCHU-PUFAs enriched PLs are used for synthesis of new membranes of disk and vesicles of OS of rods and cones and tenaciously retained in the bilayer closer to the molecules of rhodopsin and to the other visual pigments. Damaged or aged disks slowly migrate contacting the intricated cytoplasmic extensions of PEC where they are engulfed and digested within PEC lysosomes (see Figs. 1 and 3). DHA and other $\omega 3$ and $\omega 6$ LCHU-PUFAs are separated and esterified in triglycerides, stored in the abundant oil droplets of PEC and then re-uptaked by myoid area of rod and cones $[8,12,82,103$, 104].

These highly and selective needs for $\omega 3$ and $\omega 6$ LCHU-PUFAs for efficient morpho-physiology of retina highlights the sensible dependence of enough supply of dietary precursor (the EFAs $\omega 3$-ALA and $\omega 6-\mathrm{AA}$ ) of these LCHU-PUFAs. Even though the human body (mainly the liver) potentially have the capabilities to desaturate and elongate EFAs for satisfice the needs of highly differentiated retinal populations, these are unusually high (see Fig. 1). Accordingly, when an experimental deprivation of $\omega 3$ and $\omega 6$ LCHU-PUFAs is induced these lipids are strongly retained by retinal PRs; if this deficiency is maintained finally the visual acuity become altered [105, 106]. Unfortunately, the food sources of formed LCHU-PUFAs, particularly those enriched in $\omega 3$ LCHU-PUFAs, are very scarce in the so called western diets thus supporting the need of dietary intervention or nutrient supplementation, even in healthy pregnancy, childhood and elderly [67, 107]. Hence, if the desaturation and elongation of $\omega 3$-ALA and $\omega 6$-AA become abnormal, as happens in several metabolic diseases including DM, the fresh supply of $\omega 3$ and $\omega 6$ LCHU-PUFAs for rod and cones become progressively deficitary. Progressive blockade of activities of $\Delta 9, \Delta 6$ and $\Delta 5$ desaturases have been consistently described in DM animals and humans as said before [108, 109]. Actually, DM patients shows lower concentrations of LCHU-PUFAs whereas saturated FA and monoenes, mainly OA and derivatives, are higher [110]. In a DM rat model, a decrease in FA elongases activities were observed with decreased incorporation of LCHU-PUFAs in retinal PLs and increased markers of inflammation [14, 18]. Promisingly DM2 middle-aged and elderly patients enroled in the "Prevención con Dieta Mediterranea" (PREDIMED) study, after 6 years of follow up those adherents to Mediterranean dietary habits, particularly those whose foods included $\omega 3$-LCHU-PUFAs (around $500 \mathrm{mg} /$ day), showed prolonged preservation of retinal neuronal functions [111]. For practical purposes to the clinician a well summarized table of the putative beneficial actions of $\omega 3$-LCHU-PUFAs supplementation in DMRP and its major complication, the age related macular degeneration, is giving by San Giovanni and Chew (2005) [12].

\section{Autoimmune response and disruption of blood retinal barrier (BRB) in DM}

Since each of the three embryonic layers of the eye will differentiate in particularly cell populations, a vast number of new epitopes will appear throughout the pre- and post- natal development, some of them being highly sensible if recognized by the IS of the own subject, thus becoming propense to trigger an autoimmune disease in the eye globe. When inner and/or outer BRB become disrupted, these "not-recognized" molecules become target sites for the IS response. BLs as eicosanoids, may differentially affect the activities of such molecules, as ILs, distorting their functions [12, 112, 113]. Coincidently, lower levels of anti-inflammatory IL-10 were comparatively detected in plasma and tissue B lymphocytes of patients suffering of DMRP [114]. In a model of DM rats BRB permeability, assayed with Evans Blue (EB) dye, it was altered at six months of disease, whereas the amount of tight junction proteins decreased significantly. The treatment with TNFSF15, an endogenous neovascularization inhibitor and strong negative regulator of vascular homeostasis, protected the BRB functions [115]. In advanced stages of DM, measures of TL1A levels, a variety of proinflammatory TNF- $\alpha$, in the retina and vitreous were significantly increased. In addition, values for VEGF, TNF- $\alpha$ and IL- $1 \beta$ in the retina and vitreous were comparatively higher at 3 and 6 months in the DM [23]. As illustrated (Figs. 3 and 5) pericyte also contributes to 
impermeability of the BRB. Actually, it was showed that pericyte apoptosis in diabetes may cause a subtle abnormal immune response as demonstrated by in vitro study pointing out that several retinal autoantibodies may induce pericyte death followed by the complement system activation [116].

\section{Intraretinal low grade chronic inflammation (LGCI) in DM} Consistently experimental, cohort and clinical studies showed that in DMRP characteristics signs of LGCI develops. This issue has been thoroughly revised by Das $[15,28]$ and other authors $[52,117]$. Indeed, under ophthalmoscopic examination increased diameter of retinal vessels with augmented blood flow and eventually blood stasis, followed by leakage of plasma are observed. These lesions are accompanied by proteins leakage, BLs release, leucocyte lodging, diapedesis and migration of lymphocytes. Microscopical examination of the retina allows to corroborate inflammatory cells colonization (Figs. 4 and 5). Attachment and diapedesis of inflammatory cells may be linked to increased synthesis of TNF- $\alpha$, VEGFs, series-2 PGs, enhanced expression of ICAM-1 on the blood vessels bed. Also, expression of integrins, as laminin, fibronectin and vascular cell adhesion molecule-1 (VCAM-1) arise on leucocytes cell membranes. Taken as a whole this scenario also indicate augmented oxidative stress [118]. Rheological disturbances in the blood flow causes increased synthesis of several reactive oxygen species (ROS) and lipid peroxidation [119]. Eventually a slow and progressive loss of permeability of the BRB develops along with endothelial disfunction, followed by pericytes apoptosis and endothelial denudation. In a following stage retinal capillaries will suffer periods of ischemia followed by reperfusion [120]. Interesting, patients with rheumatoid arthritis also suffering of DMRP treated with anti-inflammatory NSAIDs as aspirin at higher doses showed comparatively less severe retinal histopathological alterations [121]. These effects may be due to diminution in the synthesis of COX-2 derivatives as PGs, prostacyclines, TXs and inflammatory COX2-endocannabinoids derivates $[2,32,118,120]$. In addition DMRP patients exhibited reduced plasma and vitreal concentrations of two key vasodilators, PGE1 and PGI2 whereas TXB2 and LTs were increased along with high vitreous expression of TNF- $\alpha$, IL1 and IL6 [122, 123]. As happens in other vascular beds in diabetic patients, in DMRP there is also a loss of homeostatic balance between vasodilator and platelet anti-aggregator effects against platelet aggregator and vasoconstrictors response induced by TXA2 and LTs, being this one of the causes of the alterations of ischemic vasoconstriction and reperfusion of retinal vessels, scenario aggravated by activation of platelet aggregation and clotting trend [10].

\section{Conclusions and recommendation for healthy practices in long standing diabetic patients in risk of diabetic- linked retinopathy}

As analyzed, DMRP and its accompanying lesions constitute a frequent ocular complication in long-standing diabetic patients. These illnesses, along with other associated chronic diseases such as obesity, overweight, some cancers, several heart diseases, dyslipidemias and hypertension, have in common a persistent condition of LGCI [4, 15, 28, 93]. Once this scenario is generated, which usually takes a long asymptomatic time, an imbalance is established and maintained between a decreased synthesis of anti-inflammatory components such as some cytokines and bioactive lipids (as resolvins, maresins and protectins) derivatives of $\omega 3$ or $\omega 6$ LC-PUFAs, on the one hand, and simultaneously, a sustained increase in plasma (and intraocular) proinflammatory cytokines, PGs, pro-inflammatory eicosanoids, leukotrienes, certain growth factors (as VEGF), free radicals, ROS and several auto-antibodies. Abnormal or deficient availability of essential $\omega 3$ PUFA in foods and/or cell membranes, indeed take place due to unhealthy dietary practices as are consumption of foods very rich in saturated fats, or genetically modified sunflower oil enriched in non- essential $\omega 9$ oleic acid, and simple sugars, since a chronic subclinical or border-line w3/w6D may occur. Hence It seems beneficial to start with easy attempts devoted to stimulate those anti-inflammatory molecules that the organism naturally produces, finished apparently simple measures, sustained throughout the life span of the DM patients, in order to prevent and to attenuate the visual complications of long-standing DM (Fig. 7). Beside the scheduled controls with the ophthalmologist, these measures include, in the broad sense, a global lifestyle change, including a strict control of blood glucose avoiding sudden, extreme and continuous fluctuations in glycemic values, strict weight control, healthy dietary habits with low intake of fatty meats, saturated and/or processed fats, increased intake of vegetables and legumes and few lean meats. More meals containing "blue fishes" rich in $\omega 3$ (mackerel, salmon, herring, tuna, sardine, containing up $10 \%$ of fats), daily exercise of moderate intensity, such as cycling in the plain, or fixed bicycle, walks outside at a brisk pace, or on mechanical treadmills $(5 \mathrm{~km} / \mathrm{h})$ for 30 $45 \mathrm{~min}$. Because the intake of $\omega 3$ rich-fishes is usually scarce in the West diet, due to cultural reasons, availability and / or higher costs, it is advisable exogenous daily per os administration of well- sealed fish oil capsules enriched in $\omega 3$-EPA and $\omega 3$-DHA, usually containing of $1000 \mathrm{mg}$, (recommended dose: $2000 \mathrm{mg} /$ day), immediately before the meals.

\section{Abbreviations}

AA: w6-arachidonic acid; BLs: Bioactive lipids derivatives; BM: Basal membrane; BRB: Blood retinal barrier; CNS: Central nervous system; DH: w3-docosahexaenoic acid; DM: Diabetes mellitus; DMRP: Diabetes 
mellitus- linked retinopathy; EFAs: Essential fatty acids; EPA: $\omega 3$ eicosapentaenoic acid; FA: Fatty acids; IL: Interleukin; IS: Immunological system; LCHU-PUFAs: Long chained highly unsaturated polyunsaturated fatty acids; LGCl: Low grade chronic inflammation; LTs: Leukotrienes; OBRB: Outer blood retinal barrier; OS: Outer segment; PEC: Pigmented epithelial cells; PGs: Prostaglandins; PLs: Phospholipid; PM: Plasma membrane; PRs: Photoreceptors; PUFAs: Polyunsaturated fatty acids; VEGF: Vascular endothelial growth factor; w3/w6D: $\omega 3$ and w6 PUFA deficiency; ZA: Zonulae adherens; ZO: Zonulae occludens

\section{Acknowledgements}

Not applicable.

\section{Funding}

The authors did not have funds from any institution to carry out this work.

\section{Availability of data and materials}

Not applicable.

\section{Authors' contributions}

ARE and GR designed, wrote and corrected this work. Both authors read and approved the final manuscript.

\section{Ethics approval and consent to participate}

Not applicable.

\section{Consent for publication}

All authors have read and approved the manuscript for publication.

\section{Competing interests}

The authors declare that they have no competing interests.

\section{Publisher's Note}

Springer Nature remains neutral with regard to jurisdictional claims in published maps and institutional affiliations.

\section{Received: 13 November 2018 Accepted: 12 April 2019}

Published online: 15 May 2019

\section{References}

1. Dain A, Repossi G, Das UN, Eynard AR. Role of polyunsaturated fatty acids, the precursors of endocannabinoids, in human obesity and diabetes development. Front Biosci. 2010;E2:1432-47.

2. Dain A, Repossi G, Diaz-Gerevini GT, Vanamala J, Das UN, Eynard AR. Long chain polyunsaturated fatty acids (LCPUFAs) and nordihydroguaiaretic acid (NDGA) modulate metabolic and inflammatory markers in a spontaneous type 2 diabetes mellitus model (Stillman Salgado rats). Lipids Health Dis. 2016;15(1):205

3. Grosick R, Alvarado-Vazquez PA, Messersmith AR, Romero-Sandoval EA. High glucose induces a priming effect in macrophages and exacerbates the production of pro-inflammatory cytokines after a challenge. J Pain Res. 2018;11:1769-78.

4. Díaz-Gerevini GT, Repossi G, Dain A, Tarrés MC, Das UN, Eynard AR. Cognitive and motor perturbations in elderly with longstanding diabetes mellitus. Nutrition. 2014;30(6):628-35.

5. Chen WC, Lee CC, Chien MN, Liu SC, Wang CH, Yang WS. Blood glucose Management of Type 2 diabetes in the older people. Int J Gerontology. 2018;12(3):170-4.

6. World Health Organization. Global report on diabetes. http://apps.who.int/ iris/bitstream/10665/204871/1/9789241565257_eng.pdf?ua=1. Accessed 6 Dec 2018.

7. Blatt D, Gostic CL. Reducing the Risk of Diabetes and Metabolic Syndrome With Exercise and Physical Activity. In: Bagchi D, Nair S, editors. Nutritional and Therapeutic Interventions for Diabetes and Metabolic Syndrome. New York: Academic Press; 2018. p. 315-27.

8. Gong Y, Fu Z, Liegl R, Chen J, Hellström A, Smith LE. $\omega 3$ and $\omega-6$ long-chain PUFAs and their enzymatic metabolites in neovascular eye diseases. Am J Clin Nutr. 2017;106(1):16-26.

9. Rübsam A, Parikh S, Fort PE. Role of Inflammation in Diabetic Retinopathy. Int J Mol Sci. 2018;19(4). https://doi.org/10.3390/ijms19040942.
10. Behl T, Kaur I, Kotwania A. Role of leukotrienes in diabetic retinopathy. Prostaglandins Other Lipid Mediat. 2016;122:1-9.

11. Jafari T, Fallah AA, Azadbakht L. Role of dietary n-3 polyunsaturated fatty acids in type 2 diabetes: a review of epidemiological and clinical studies. Maturitas. 2013;74(4):303-8.

12. San Giovanni JP, Chew EY. The role of omega-3 long-chain polyunsaturated fatty acids in health and disease of the retina. Prog Retin Eye Res. 2005; 24(1):87-138.

13. Yanagida K, Hla T. A dark side to omega-3 fatty acids. Nature. 2017; 552(7684):180-1.

14. Tikhonenko M, Lydic TA, Opreanu M, Li Calzi S, Bozack S, McSorley KM, Sochacki AL, Faber MS, Hazra S, Duclos S, Guberski D, Reid GE, Grant MB, Busik JV. N-3 polyunsaturated fatty acids prevent diabetic retinopathy by inhibition of retinal vascular damage and enhanced endothelial progenitor cell reparative function. PLoS One. 2013:8(1):e55177.

15. Das UN. Lipoxins, resolvins, and protectins in the prevention and treatment of diabetic macular edema and retinopathy. Nutrition. 2013;29:1-7.

16. Li S, Zhou T, Li C, Dai Z, Che D, Yao Y, Li L, Ma J, Yang X, Gao G. High metastatic gastric and breast cancer cells consume oleic acid in an AMPK dependent manner. PLoS One. 2014;9(5):e97330.

17. Simon MV, Agnolazza DL, Lorena O, Garelli GA, Politi LE, Agbaga MP, Anderson RE, Rotstein NP. Synthesis of docosahexaenoic acid from eicosapentaenoic acid in retina neurons protects photoreceptors from oxidative stress. J Neurochem. 2016;136:931-46.

18. Tikhonenko M, Lydic TA, Wang Y, Chen W, Opreanu M, Sochacki A, McSorley KM, Renis RL, Kern T, Jump DB, Reid GE, Busik JV. Remodeling of retinal fatty acids in an animal model of diabetes: a decrease in long-chain polyunsaturated fatty acids is associated with a decrease in fatty acid elongases Elovl2 and Elovl4. Diabetes. 2010;59(1):219-27.

19. Sasaki M, Kawasaki R, Rogers S, Man RE, Itakura K, Xie J, Flood V, Tsubota K, Lamoureux E, Wang JJ. The associations of dietary intake of polyunsaturated fatty acids with diabetic retinopathy in well-controlled diabetes. Invest Ophthalmol Vis Sci. 2015;56(12):7473-9.

20. Stein-Streilein J. Mechanisms of immune privilege in the posterior eye. Int Rev Immunol. 2013;32(1):42-56. https://doi.org/10.3109/08830185. 2012.740535.

21. Detrick B, Gangaputra S, Palsgrove DN, Heaney CD, Hooks JJ, Nida SH. Elevated serum levels of IL-6 and CXCL9 in autoimmune retinopathy (AIR) patients. J Neuroimmunol. 2018;316:74-9.

22. Rahi AH, Addison DJ. Autoimmunity and the outer retina. Trans Ophthalmol Soc UK. 1983;103(4):428-37.

23. Zhang ZH, Chen QZ, Jiang F, Townsend TA, Mao CJ, You CY, Yang WH, Sun ZY, Yu JG, Yan H. Changes in TL1A levels and associated cytokines during pathogenesis of diabetic retinopathy. Mol Med Rep. 2017;15(2):573-80.

24. Dong YH, Fu DG. Autoimmune thyroid disease: mechanism, genetics and current knowledge. Eur Rev Med Pharmacol Sci. 2014;18(23):3611-8.

25. James EA, Pietropaolo M, Mamula MJ. Immune recognition of $\beta$-cells: Neoepitopes as key players in the loss of tolerance. Diabetes. 2018; 67(6):1035-42.

26. Clark M, Kroger CJ, Tisch RM. Type 1 diabetes: a chronic anti-selfinflammatory response. Front Immunol. 2017:8:1898.

27. Hammer SS, Busik JV. The role of dyslipidemia in diabetic retinopathy. Vis Res. 2017:139:228-36.

28. Das UN. Diabetic macular edema, retinopathy and age-related macular degeneration as inflammatory conditions. Arch Med Sci. 2016:12(5):1142-57.

29. Huang C, Zhu HJ, Li H, Li QX, Li FM, Cheng L, Liu YG. p38-MAPK pathway is activated in retinopathy of microvascular disease of STZ-induced diabetic rat model. Eur Rev Med Pharmacol Sci. 2018;22(18):5789-96.

30. Zorrilla-Zubilete MA, Yeste A, Quintana FJ, Toiber D, Mostoslavsky R, Silberman DM. Epigenetic control of early neurodegenerative events in diabetic retinopathy by the histone deacetylase SIRT6. J Neurochem. 2018; 144(2):128-38.

31. Hoshino A, Ratnapriya R, Brooks MJ, Chaitankar V, Wilken MS, Zhang C, Starostik MR, Gieser L, La Torre A, Nishio M, Bates O, Walton A, BerminghamMcDonogh O, Glass IA, Wong ROL, Swaroop A, Reh TA. Molecular anatomy of the developing human retina. Dev Cell. 2017:43:763-79.

32. Crowley RK, O'Reilly MW, Bujalska IJ, Hassan-Smith ZK, Hazlehurst JM, Foucault DR, Stewart PM, Tomlinson JW. SFRP2 is associated with increased adiposity and VEGF expression. PLoS One. 2016;11(9):e0163777.

33. Horai R, Silver PB, Chen J, Agarwal RK, Chong WP, Jittayasothorn $Y$, Mattapallil MJ, Nguyen S, Natarajan K, Villasmil R, Wang P, Karabekian Z, 
Lytton SD, Chan CC, Caspi RR. Breakdown of immune privilege and spontaneous autoimmunity in mice expressing a transgenic $\mathrm{T}$ cell receptor specific for a retinal autoantigen. J Autoimmun. 2013;44:21-33.

34. Jastrow H., Human Retina. In: Electron microscopic atlas of cells, tissues and organs in the Internet. http://www.drjastrow.de/WAI/EM/EMHRetinaE.html. Accessed 17 Apr 2019

35. Nag TC, Wadhwa S. Ultrastructure of the human retina in aging and various pathological states. Micron. 2012;43(7):759-81.

36. Chawla R, Tripathy K, Temkar S, Kumar V. Internal limiting membrane: The innermost retinal barrier. Med Hypotheses. 2017;98:60-2.

37. Díaz-Coránguez $\mathrm{M}$, Ramos C, Antonetti DA. The inner blood-retinal barrier: cellular basis and development. Vis Res. 2017;139:123-37.

38. Gosselet F. Modelling of the blood-brain barrier. Med Sci (Paris). 2017;33(4):423-31.

39. Haseloff RF, Dithmer S, Winkler L, Wolburg H, Blasig IE. Transmembrane proteins of the tight junctions at the blood-brain barrier: structural and functional aspects. Semin Cell Dev Biol. 2015;38:16-25.

40. Chauhan B, Plageman T, Lou M, Lang R. Epithelial morphogenesis: the mouse eye as a model system. Curr Top Dev Biol. 2015;111:375-99.

41. Nguyen-Legros J, Hicks D. Renewal of photoreceptor outer segments and their phagocytosis by the retinal pigment epithelium. Int Rev Cytol. 2000; 196:245-313.

42. Anderson DH, Fisher SK, Steinberg RH. Mammalian cones: disc shedding, phagocytosis, and renewal. Invest Ophthalmol Vis Sci. 1978;17(2):117-33.

43. Mruk DD, Cheng CY. The mammalian blood-testis barrier: its biology and regulation. Endocr Rev. 2015;36(5):564-91.

44. El-Sayyad HI, Khalifa SA, El-Sayyad FI, Mousa SA, Mohammed EA. Analysis of fine structure and biochemical changes of retina during aging of Wistar albino rats. Clin Exp Ophthalmol. 2014;42(2):169-81.

45. Sinha D, Valapala M, Shang P, Hose S, Grebe R, Lutty GA, Zigler JS Jr, Kaarniranta K, Handa JT. Lysosomes: regulators of autophagy in the retinal pigmented epithelium. Exp Eye Res. 2016;144:46-53.

46. Ferrington DA, Sinha D, Kaarniranta K. Defects in retinal pigment epithelial cell proteolysis and the pathology associated with age-related macular degeneration. Prog Retin Eye Res. 2016;51:69-89.

47. Agbaga MP, Mandal NA, Anderson RE. Retinal very long chain polyunsaturated fatty acids: new insights from studies on ELOVL4 protein. J Lipid Res. 2010;51(7):1624-42.

48. Cunha-Vaz J, Bernardes R, Lobo C. Blood-retinal barrier. Eur J Ophthalmol. 2011;21(6):S3-9.

49. Benedicto I, Lehmann GL, Ginsberg M, Nolan DJ, Bareja R, Elemento O, Salfati Z, Alam NM, Prusky GT, Llanos P, Rabbany SY, Maminishkis A, Miller SS, Rafii S, Rodriguez-Boulan E. Concerted regulation of retinal pigment epithelium basement membrane and barrier function by angiocrine factors. Nat Commun. 2017:8:15374.

50. Omri S, Behar-Cohen F, de Kozak Y, Sennlaub F, Verissimo LM, Jonet L, Savoldelli M, Omri B, Crisanti P. Microglia/macrophages migrate through retinal epithelium barrier by a transcellular route in diabetic retinopathy: role of PKCद in the Goto Kakizaki rat model. Am J Pathol. 2011;179(2):942-53.

51. Simo R, Villarroel M, Corraliza L, Hernandez C, Garcia-Ramirez M. The retinal pigment epithelium: something more than a constituent of the blood retinal barrier: implications for the pathogenesis of diabetic retinopathy. J Biomed Biotechnol. 2010;2010:190724.

52. Klaassen I, Van Noorden CJ, Schlingemann RO. Molecular basis of the inner blood-retinal barrier and its breakdown in diabetic macular edema and other pathological conditions. Prog Retin Eye Res. 2013;34:19e48.

53. Frey T, Antonetti DA. Alterations to the blood-retinal barrier in diabetes: cytokines and reactive oxygen species. Antioxid Redox Signal. 2011; 15(5):1271-84

54. Xu HZ, Le YZ. Significance of outer blood-retina barrier breakdown in diabetes and ischemia. Invest Ophthalmol Vis Sci. 2011;52(5):2160-4.

55. Omri S, Behar-Cohen F, Rothschild PR, Gélizé E, Jonet L, Jeanny JC, Omri B, Crisanti P. PKC mediates breakdown of outer blood-retinal barriers in diabetic retinopathy. PLoS One. 2013;8(11):e81600.

56. Krügel K, Wurm A, Pannicke T, Hollborn M, Karl A, Wiedemann P, Reichenbach A, Kohen L, Bringmann A. Involvement of oxidative stress and mitochondrial dysfunction in the osmotic swelling of retinal glial cells from diabetic rats. Exp Eye Res. 2011;92(1):87-93.

57. Malaguti C, La Guardia PG, Leite AC, Oliveira DN, de Lima Zollner RL, Catharino $R R$, Vercesi AE, Oliveira HC. Oxidative stress and susceptibility to mitochondrial permeability transition precedes the onset of diabetes in autoimmune nonobese diabetic mice. Free Radic Res. 2014;48(12):1494-504.
58. Eynard AR, Cejas V, Silva R, Quiroga P, Muñoz S. Histopathology of the essential fatty acid deficient mice. Nutrition. 1992;8:37-40.

59. Hu J, Dziumbla S, Lin J, Bibli SI, Zukunft S, de Mos J, Awwad K, Frömel T, Jungmann A, Devraj K, Cheng Z, Wang L, Fauser S, Eberhart CG, Sodhi A, Hammock BD, Liebner S, Müller OJ, Glaubitz C, Hammes HP, Popp R, Fleming I. Inhibition of soluble epoxide hydrolase prevents diabetic retinopathy. Nature. 2017;552(7684):248-52.

60. Eynard AR, Monis B, Kalinec F, Leguizamon RO. Increased proliferation of the epithelium of the proximal alimentary tract of EFA- deficient rats. A light and electron microscopy study. Exp Mol Pathol. 1982;36:135-43.

61. Eynard AR, Jiang WG, Mansel RE. Eicosatrienoic acid (20:3n-9) inhibits the expression of E-cadherin and desmoglein in human squamous cell carcinoma in vitro. Prostaglandins Leukot Essent Fat Acids. 1998;59(6):371-7.

62. Jiang WG, Eynard AR, Mansel RE. The pathology of essential fatty acid (EFA) deficiency is it cell adhesion mediated? Med Hypoth. 2000;55:257-62.

63. Heyd VL, Eynard AR. Effects of eicosatrienoic acid (20:3 n-9, Mead's acid) on some promalignant-related properties of three human cancer cell lines. Prostaglandins Other Lipid Mediat. 2003;71(3-4):177-88.

64. Eynard AR, Navarro A. Crosstalk among dietary polyunsaturated fatty acids, urolithiasis, chronic inflammation, and urinary tract tumor risk. Nutrition. 2013:29(7-8):930-8.

65. Sassa T, Ohno Y, Suzuki S, Nomura T, Nishioka C, Kashiwagi T, Hirayama T, Akiyama M, Taguchi R, Shimizu H, Itohara S, Kihara A. Impaired epidermal permeability barrier in mice lacking elovl1, the gene responsible for verylong-chain fatty acid production. Mol Cell Biol. 2013;33(14):2787-96.

66. Zhao J, Shi P, Sun Y, Sun J, Dong JN, Wang HG, Zuo LG, Gong JF, Li Y, Gu LL, Li N, Li JS, Zhu WM. DHA protects against experimental colitis in IL-10deficient mice associated with the modulation of intestinal epithelial barrier function. Br J Nutr. 2015;114(2):181-8.

67. Das UN. Essential fatty acids - a review. Curr Pharm Biotechnol. 2006; 7(6):467-82.

68. Zhang W, Zhang H, Mu H, Zhu W, Jiang X, Hu X, Shi Y, Leak RK, Dong Q, Chen J, Gao Y. Omega-3 polyunsaturated fatty acids mitigate blood-brain barrier disruption after hypoxic-ischemic brain injury. Neurobiol Dis. 2016;91:37-46.

69. Coquenlorge S, Van Landeghem L, Jaulin J, Cenac N, Vergnolle N, Duchalais E, Neunlist M, Rolli-Derkinderen M. The arachidonic acid metabolite 11ßprostaglandin F2a controls intestinal epithelial healing: deficiency in patients with Crohn's disease. Sci Rep. 2016;3(6):25203.

70. Nobeschi L, Freymuller E, Smith RL. Intercellular junctions in rabbit eye ora serrata. Anat Histol Embryol. 2006:35(5):287-92.

71. Najor NA. Desmosomes in human disease. Annu Rev Pathol. 2018;13:51-7.

72. Ismail AF, Oskay Halacli S, Babteen N, De Piano M, Martin TA, Jiang WG, Khan MS, Dasgupta P, Wells CM. PAK5 mediates cell: cell adhesion integrity via interaction with E-cadherin in bladder cancer cells. Biochem J. 2017; 474(8):1333-46.

73. Lämmermann T, Afonso PV, Angermann BR, Wang JM, Kastenmüller W, Parent CA, Germain RN. Neutrophil swarms require LTB4 and integrins at sites of cell death in vivo. Nature. 2013;498(7454):371-5.

74. Valenzano MC, DiGuilio K, Mercado J, Teter M, To J, Ferraro B, Mixson B, Manley I, Baker V, Moore BA, Wertheimer J, Mullin JM. Remodeling of tight junctions and enhancement of barrier integrity of the CACO-2 intestinal epithelial cell layer by micronutrients. PLoS One. 2015;10(7):e0133926.

75. Beguin $\mathrm{P}$, Errachid A, Larondelle Y, Schneider YJ. Effect of polyunsaturated fatty acids on tight junctions in a model of the human intestinal epithelium under normal and inflammatory conditions. Food Funct. 2013;4(6):923-31.

76. Livingstone KM, Givens DI, Jackson KG, Lovegrove JA. Comparative effect of dairy fatty acids on cell adhesion molecules, nitric oxide and relative gene expression in healthy and diabetic human aortic endothelial cells. Atherosclerosis. 2014;234(1):65-72.

77. Hu P, Meyers S, Liang FX, Deng FM, Kachar B, Zeidel ML, Sun TT. Role of membrane proteins in permeability barrier function: uroplakin ablation elevates urothelial permeability. Am J Physiol Renal Physiol. 2002;283:F1200-7.

78. Min G, Zhou G, Matthieu S, Sun TT, Kong XP. Structural basis of urothelial permeability barrier function as revealed by Cryo-EM studies of the $16 \mathrm{~nm}$ uroplakin particle. J Cell Sci. 2003;116:4087-94.

79. Grasso EJ, Calderón RO. Urinary bladder membrane permeability differentially induced by membrane lipid composition. Mol Cell Biochem. 2009:330(1-2):163-9.

80. Grasso EJ, Scalambro MB, Calderón RO. Differential response of the urothelial V-ATPase activity to the lipid environment. Cell Biochem Biophys. 2011;61(1):157-68 
81. Gorusupudi A, Liu A, Hageman GS, Bernstein PS. Associations of human retinal very long-chain polyunsaturated fatty acids with dietary lipid biomarkers. J Lipid Res. 2016;57(3):499-508.

82. Senapati S, Gragg M, Samuels IS, Parmar VM, Maeda A, Park PSH. Effect of dietary docosahexaenoic acid on rhodopsin content and packing in photoreceptor cell membranes. Biochim Biophys Acta Biomembr. 2018; 1860(6):1403-13.

83. Andrade LC, Souza GS, Lacerda EM, Nazima MT, Rodrigues AR, Otero LM, Pena FP, Silveira LC, Côrtes MI. Influence of retinopathy on the achromatic and chromatic vision of patients with type 2 diabetes. BMC Ophthalmol. 2014;14:104.

84. Gella L, Raman R, Kulothungan V, Pal SS, Ganesan S, Sharma T. Impairment of colour vision in diabetes with no retinopathy: Sankara Nethralaya diabetic retinopathy epidemiology and molecular genetics study (SNDREAMS- II, report 3). PLoS One. 2015;10(6):e0129391.

85. Serhan CN, Dalli J, Colas RA, Winkler JW, Chiang N. Protectins and maresins: new pro-resolving families of mediators in acute inflammation and resolution bioactive metabolome. Biochim Biophys Acta. 2015;1851(4):397-41.

86. Calder PC. Marine omega-3 fatty acids and inflammatory processes: effects, mechanisms and clinical relevance. Biochim Biophys Acta. 2015; 1851(4):469-84.

87. Das UN. Arachidonic acid in health and disease with focus on hypertension and diabetes mellitus: a review. J Adv Res. 2018;11:43-55.

88. Daak AA, Elderdery AY, Elbashir LM, Mariniello K, Mills J, Scarlett G, Elbashir MI, Ghebremeskel K. Omega 3 (n-3) fatty acids down-regulate nuclear factor-kappa B (NF-kB) gene and blood cell adhesion molecule expression in patients with homozygous sickle cell disease. Blood Cells Mol Dis. 2015; 55(1):48-55

89. Calderon RO, Eynard AR. Fatty acids specifically related to the anisotropic properties of plasma membrane from rat urothelium. Biochim Biophys Acta. 2000;1483(1):174-84

90. Jastrow H, Yarwood A, Majorovits E, Harris JR. Tomographic reconstruction reveals the morphology of a unique cellular organelle, the aggregated macrotubules (Macrotubuli aggregati) of human retinal horizontal cells. Tissue Cell. 2015;47(2):186-97.

91. Yasuda S, Hara H, Tokunaga F, Arata T. Spatial arrangement of rhodopsin in retinal rod outer segment membranes studied by spinlabeling and pulsed electron double resonance. Biochem Biophys Res Commun. 2012;425(2):134-7

92. Kessler C, Tillman M, Burns ME, Pugh EN Jr. Rhodopsin in the rod surface membrane regenerates more rapidly than bulk rhodopsin in the disc membranes in vivo. J Physiol. 2014;592(13):2785-97.

93. Das UN. Metabolic syndrome pathophysiology: the role of essential fatty acids. Boston: Wiley-Blackwell; 2010.

94. Das UN. Molecular basis of health and diseases. Heidelberg: Springe editors; 2011.

95. Repossi G, Dain A, Eynard AG. Dietary manipulations of polyunsaturated fatty acids (PUFA) substrates of endocannabinoids: implications in human health and diseases. Curr Nutr Food Sci. 2009;5(2):112-25.

96. Díaz-Gerevini GT, Daín A, Pasqualini ME, López CB, Eynard AR, Repossi G. Diabetic encephalopathy: beneficial effects of supplementation with fatty acids $\omega 3$ and nordihydroguaiaretic acid in a spontaneous diabetes rat model. Lipids Health Dis. 2019;18(1):43.

97. Aiello LP, DCCT/EDIC Research Group. Diabetic retinopathy and other ocular findings in the diabetes control and complications trial/ epidemiology of diabetes interventions and complications study. Diabetes Care. 2014;37(1):17-23.

98. Brett GJ, Neuringer M. Age-related decline in rod Phototransduction sensitivity in rhesus monkeys fed an n-3 fatty acid deficient diet. Invest Ophthalmol Vis Sci. 2009;50(9):4360-7.

99. Liu A, Terry R, Nelson K, Sheng X, Bernstein PS. Diet Can Influence Human Retinal n-3/n-6 VLC-PUFA Ratios. Invest Ophthalmol Vis Sci. 2012;53:6502.

100. Lecomte M, Paget C, Ruggiero D, Wiernsperger N, Lagarde M. Docosahexaenoic acid is a major $n-3$ polyunsaturated fatty acid in bovine retinal microvessels. J Neurochem. 1996;66(5):2160-7.

101. Bazan NG, Gordon WC, Rodriguez de Turco EB. Docosahexaenoic acid uptake and metabolism in photoreceptors: retinal conservation by an efficient retinal pigment epithelial cell-mediated recycling process. Adv Exp Med Biol. 1992;318:295-306.
102. Li F, Chen H, Anderson RE. Biosynthesis of docosahexaenoatecontaining glycerolipid molecular species in the retina. J Mol Neurosci. 2001;16(2-3):205-21.

103. Bibb C, Young RW. Renewal of fatty acids in the membranes of visual cell outer segments. J Cell Biol. 1974;61:327-43.

104. Bennett LD, Brush RS, Chan M, Lydic TA, Reese K, Reid GE, Busik JV, Elliott $\mathrm{MH}$, Anderson RE. Effect of reduced retinal VLC-PUFA on rod and cone photoreceptors. Invest Ophthalmol Vis Sci. 2014;55(5):3150-7.

105. Bazan NG, Reddy TS, Bazan HE, Birkle DL. Metabolism of arachidonic and docosahexaenoic acids in the retina. Prog Lipid Res. 1986;25(1-4):595-606.

106. Hoffman DR, Boettcher JA, Diersen-Schade DA. Toward optimizing vision and cognition in term infants by dietary docosahexaenoic and arachidonic acid supplementation: a review of randomized controlled trials. Prostaglandins Leukot Essent Fatty Acids. 2009;81(2-3):151-8.

107. Saini RK, Keum YS. Omega-3 and omega- 6 polyunsaturated fatty acids: dietary sources, metabolism, and significance - a review. Life Sci. 2018, 203:255-67.

108. Das UN. A defect in the activity of Delta6 and Delta5 desaturases may be a factor predisposing to the development of insulin resistance syndrome. Prostaglandins Leukot Essent Fatty Acids. 2005;72(5):343-50.

109. Imamura S, Morioka T, Yamazaki Y, Numaguchi R, Urata H, Motoyama K, Mori K, Fukumoto S, Shoji T, Emoto M, Inaba M. Plasma polyunsaturated fatty acid profile and delta-5 desaturase activity are altered in patients with type 2 diabetes. Metabolism. 2014;63(11):1432-8.

110. Bhathena SJ. Relationship between fatty acids and the endocrine system. Biofactors. 2000;13(1-4):35-9.

111. Sala-Vila A, Díaz-López A, Valls-Pedret C, et al. Dietary marine $\omega$-3 fatty acids and incident sight-threatening retinopathy in middle-aged and older individuals with type 2 diabetes: prospective investigation from the PREDIMED trial. JAMA Ophthalmol. 2016;134(10):1142-9.

112. Easton AS. Regulation of permeability across the blood-brain barrier. Adv Exp Med Biol. 2012;763:1-19.

113. Lee RW, Nicholson LB, Sen HN, Chan CC, Wei L, Nussenblatt RB, Dick AD. Autoimmune and autoinflammatory mechanisms in uveitis. Semin Immunopathol. 2014;36(5):581-94.

114. Wang C, You Q, Cao X, Guo H, Gao X, Peng X. Micro RNA-19a suppresses interleukin-10 in peripheral $B$ cells of patients with diabetic retinopathy. Am J Transl Res. 2017;9(3):1410-7.

115. Jiang F, Chen Q, Huang L, Wang Y, Zhang Z, Meng X, Liu Y, Mao C, Zheng F, Zhang J, Yan H. TNFSF15 Inhibits Blood Retinal Barrier Breakdown Induced by Diabetes. Int J Mol Sci. 2016;17(5):E615.

116. Li Y, Smith D, Li Q, Sheibani N, Huang S, Kern T, Nagaraj RH, Lin F. Antibody-mediated retinal pericyte injury: implications for diabetic retinopathy. Invest Ophthalmol Vis Sci. 2012;53(9):5520-6.

117. Semeraro F, Cancarini A, dell'Omo R, Rezzola S, Romano MR, Costagliola C. Diabetic Retinopathy: Vascular and Inflammatory Disease. J Diabetes Res. 2015;2015:582060

118. Sasongko MB, Wong TY, Jenkins AJ, Nguyen TT, Shaw JE, Wang JJ. Circulating markers of inflammation and endothelial function, and their relationship to diabetic retinopathy. Diabet Med. 2015;32(5):686-91.

119. Santiago AR, Boia R, Aires ID, Ambrósio AF, Fernandes R. Sweet stress: coping with vascular dysfunction in diabetic retinopathy. Front Physiol. 2018;13(9):820.

120. Rajab HA, Baker NL, Hunt KJ, Klein R, Cleary PA, Lachin J, Virella G, LopesVirella MF. DCCT/EDIC Group of Investigators. The predictive role of markers of inflammation and endothelial dysfunction on the course of diabetic retinopathy in type 1 diabetes. J Diabetes Complicat. 2015;29(1):108-14.

121. Bergthoff K, Clar C, Richter B. Aspirin in diabetic retinopathy. A systematic review. Endocrinol Metab Clin N Am. 2002;31:779-3.

122. Demircan N, Safran BG, Soylu M, Ozcan AA, Sizmaz S. Determination of vitreous interleukin-1 (IL-1) and tumour necrosis factor (TNF) levels in proliferative diabetic retinopathy. Eye. 2006;20(12):1366-9.

123. Feng $S$, Yu H, Yu Y, Geng Y, Li D, Yang C, Lv Q, Lu L, Liu T, Li G, Yuan L. Levels of Inflammatory Cytokines IL-1 $\beta, I L-6, I L-8, I L-17 A$, and TNF- $a$ in Aqueous Humour of Patients with Diabetic Retinopathy. J Diabetes Res. 2018:8546423. https://doi.org/10.1155/2018/8546423. 